\title{
Developing physician leaders: does it work?
}

\author{
James K Stoller
}

Education, Cleveland Clinic, Cleveland, $\mathrm{OH}$, USA

Correspondence to Dr James K Stoller, Education, Cleveland Clinic, Cleveland, $\mathrm{OH}$ 44195, USA; STOLLEJ@ccf.org

Received 7 September 2018 Revised 20 December 2018 Accepted 9 January 2019

\section{ABSTRACT \\ Background Leader development programmes are signature features of frontrunner multinational companies. Healthcare institutions have generally lagged behind, though attention to implementing leader development programmes in healthcare institutions is increasing. The rationale for leader development in healthcare is that leadership competencies matter and that traditional selection and training of physicians may conspire against both optimal leadership competencies and followership.}

Methods The growth of leader development in healthcare institutions begs the question: Does leader development work?

Results In this context, three meta-analyses have examined the impact of leader development programmes in healthcare institutions. In general, findings from these studies indicate that while studies do assess the subjective learning of participants, few studies have evaluated the organisational impact of such leader development programmes.

Conclusions These findings suggest the need for more rigorous, objective assessment of the organisational impact of leader development programmes in healthcare institutions. Such evidence is critically needed in the current resource-constrained environment of healthcare.

\section{INTRODUCTION}

Leader development has been a time-honoured practice of flagship multinational corporations. ${ }^{1}$ In general, healthcare organisations have adopted such practices only more recently. In an evidence-based world, this adoption naturally begs the question: Are physician leader development programmes effective? This paper reviews the evidence regarding this question.

Three lines of reasoning have driven interest in developing physician leaders:

- Leadership competencies (eg, emotional intelligence, change management, teambuilding and so on) matter and differ from clinical and/or scientific competencies. ${ }^{2}$ In fact, it has been argued that the traditional, individualistic training of physicians (eg, 'heroic lone healers" is antithetical to leadership skills or to collaborative reflexes. ${ }^{4}$

- The complex healthcare environment that drives the triple aim of quality/patient safety, access and affordability ${ }^{5}$ requires great leadership. In support of the need for effective physician leadership, observational studies demonstrate an association between having a physician as hospital CEO and top-ranking hospital status. ${ }^{6-8}$

(c) Author(s) (or their commercial re-use. See rights and permissions. Published by BMJ.

To cite: Stoller JK. BMJ Leader 2020:4:1-5.
- The time and attention necessary to learn and master clinical and/or scientific skills eclipses attention that physicians can give to cultivating their leadership skills.

In the context of this enthusiasm for physician leadership, the current paper reviews available evidence regarding whether physician leader development programmes work. Specifically, I first review the epidemiology of physician leader development programmes. Next reviewed are the available meta-analyses that address the efficacy of physician leader development programmes. Finally, I review experience with physician leader development at Cleveland Clinic and evidence assembled from those programmes that contribute to understanding the impact of physician leader development programmes.

\section{Epidemiology of physician leader development} In front-running organisations outside of healthcare (eg, Boeing, Toyota, Motorola, Honda, General Electric) and in some healthcare institutions, leader development programmes have been adopted vigorously over the last years. However, in most healthcare organisations, uptake of physician leader development has generally been slow, though recently increasing. For example, Davidson et $a l^{9}$ interviewed 21 leaders of healthcare research organisations in 2012;57\% reported using no physician leader development programmes. Within a few years thereafter, attention to leader development for physicians has seemingly blossomed. Specifically, in a 2018 survey of 161 AAMC academic medical centres (which $58 \%$ responded, ${ }^{10}$ $45 \%$ reported having a physician leader development programme, complemented by sending faculty to outside programmes $(88 \%$ of the respondents). This observation and personal experience suggest that adoption of physician leader development programmes by healthcare institutions is rapidly increasing. As examples, healthcare systems (like the Mayo Clinic, Emory, the Cleveland Clinic, McLeod Health, Hartford Healthcare, Emory and so on) all have well-developed physician leader programmes.

\section{What is the evidence that physician leader development programmes work?}

The proliferation and popularisation of physician leader development programmes begs the question: do such programmes work?, that is, is there evidence that training physicians in leadership competencies is associated with organisational impact or benefits? Do such programmes demonstrate value? To my knowledge, four meta-analyses and key studies have addressed this issue, with concordance that the evidence for true organisational and/or clinical benefits of physician leader development programmes is relatively sparse. For example, Frich et $a l^{11}$ assessed 45 eligible studies 
unit using a Kirkpatrick scale to assess organisational impact associated with the leader development programmes. The Kirkpatrick scale $^{12}$ (from 1 to 4 ) is a training evaluation instrument that considers the impact of the training. Four impact levels are proposed: (1) Reaction-Did the learner regard the training programme as valuable?, (2) Learning-Did the learner gain knowledge from the training?, (3) Behaviour-Did the learner's behaviour change as a result of the training? and (4) Results/ impact-Was there an impact on the learner's organisation that can be ascribed to the training programme? In keeping with the analytic strategy of Frich et al, ${ }^{11}$ levels 2 through 4 are further stratified into two categories: 'A' in which the impact was subjective or self-reported and ' $\mathrm{B}$ ' in which the impact was objective and verifiable.

In the context of the Kirkpatrick evaluative scheme, few of the available studies (16\%) objectively assessed acquired knowledge (Kirkpatrick level 2), fewer (4\%) assessed concomitant behaviours (Kirkpatrick level 3) and fewer still (2\%) objectively assessed system performance (Kirkpatrick level 4).

A subsequent meta-analysis by Straus et $a l^{13}$ considered 10 eligible programmes with 636 participants (but did not stratify outcomes by Kirkpatrick levels). Four studies reportedly assessed the impact on participation in a programme on physician knowledge of leadership, with reported enhancement in all programmes. Only 3 of the programmes assessed the leadership promotion of programme attendees. In one of the few controlled studies that were reviewed by Strauss et al, ${ }^{13}$ Day et $a l^{14}$ assessed the effectiveness of a leadership development programme for orthopaedic surgeons using eight parameters: knowledge of leadership theory, environmental scanning, financial management, communication skills, conflict management, diversity competence, tolerance for the demands of leadership and leadership positioning. Programme graduates $(n=67)$ were compared with applicants who were not selected to participate $(n=73)$. Graduates were rated higher on all leadership parameters other than financial management, supporting the effectiveness of this leader development programme. As a study that included a control group and assessed leadership progression by review of study participants' curriculum vitae, this single study is among the methodologically strongest available.

In a more recent study, Lucas et $a l^{11}$ surveyed 161 Association of American Medical Colleges member institutions with a $58 \%$ response rate. A minority of respondents reported assessing postprogramme learning (38\% Kirkpatrick level 2 and only 30\% assessed postprogramme behaviour change (Kirkpatrick level 3), usually self-reported rather than objectively assessed).

Finally, a narrative meta-analysis of leader development programmes in the UK by West et $a l^{15}$ concluded: 'overall, the evidence for the effectiveness of specific leader development programmes within the National Health Service is highly variable and little robust evidence has been accumulated, despite the vast sums spent. The need to ensure effective leadership is clear but evaluating their effectiveness empirically is challenging and demonstrating positive effects on patient outcomes has proved elusive'.

In the context of these meta-analyses, table 1 summarises the findings and specific types of impacts that are reported in six of the level 4 studies of physician leader development cited by Frich et al. ${ }^{11}$ 16-21 These organisational impacts included: enhanced communication skills of intensive care unit (ICU) physicians and nurses and self-reported enhanced ICU outcomes; ${ }^{16}$ enhanced rankings on leadership indicators compared with a control group; ${ }^{17}$ impaired clinical performance due to targeted improvement projects; ${ }^{18}$ promotion to leadership roles of programme

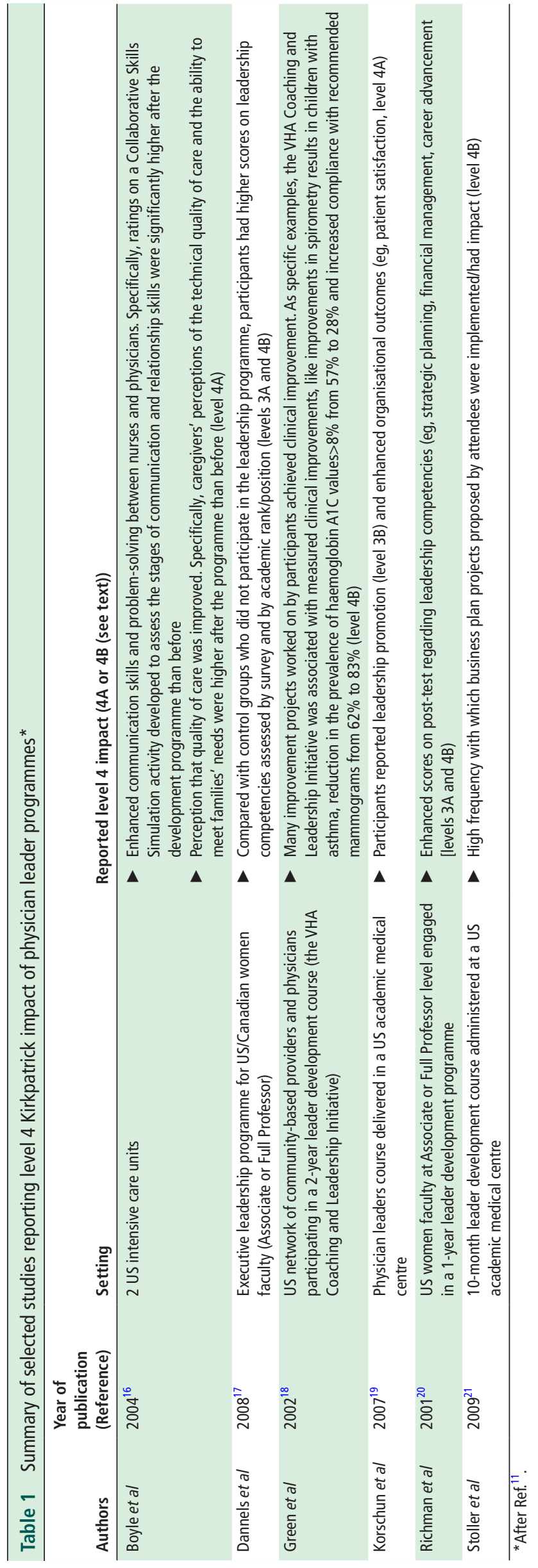




\section{Box 1 Cleveland leader development programmes}

- Leading in Health Care Course (2003-2016).

- Leadership Development for Chief Residents.

- Cleveland Clinic Lerner College of Medicine Leadership Course.

- Global Leadership and Learning Institute courses.

- Academic partnerships Clinic-CSU Masters in Health Education. Cleveland Clinic-Weatherhead School of Management Executive MBA.

- Samson Global Leadership Academy http://academy.clevelandclinic.org/

participants ${ }^{1920}$ and successful implementation of business plan proposals. ${ }^{21}$

Taken together, across multiple settings and countries, with the exception of a few rigorous studies that demonstrate favourable impact associated with physician leader development programmes from a small number of flagship institutions, ${ }^{16-23}$ the weight of evidence suggests that the answer to the question-does physician leader development work?-remains largely open and unresolved. Stated differently, there is a paucity of available controlled and well-designed studies that assess objectively measured outcomes effected by physicians after their participation in leader development programmes. This gap invites further study.

\section{Experience with physician leader development at the Cleveland Clinic}

In the context that the Cleveland Clinic is a physician-led organisation and has had a long-standing interest both in developing healthcare leaders and in assessing the impact of same, I herein describe key findings from several studies of leader development programmes from the Cleveland Clinic. ${ }^{21-23}$ The menu of healthcare provider leader development programmes at Cleveland Clinic is broad and addresses multiple audiences, from medical and nursing students, graduate medical trainees, established caregivers-physicians, nurses and administrators within the Cleveland Clinic-as well as visiting healthcare leaders. At the apex of a pyramid of offerings is the Cleveland Clinic-Weatherhead School of Management Executive MBA, which is offered as a collaboratively taught programme attended by $>50$ Cleveland Clinic caregivers since inception in 2013. Box 1 summarises the available offerings that have been provided since the launch of such programmes in 2003.

The earliest such programme, called Leading in Healthcare (LHC), began in 2003 and recruited high-potential leaders, initially physicians only (because the pipeline of physician leaders was perceived to be thinnest then) and later physicians, nurses and administrators in an interdisciplinary learning environment. Over the 13 years that LHC was offered, >520 Cleveland Clinic caregivers attended the 10-month course (which consisted of once monthly all-day sessions). Two assessments of organisational impact suggest that LHC has been highly effective. First, the capstone experience in the course for all attendees consisted of working in teams to develop a fully-fledged business plan for new organisational programmes to address current unmet, important needs. Teams of programme participants worked together over the course of the 10-month programme to prepare these business plans, which were then presented to organisational leadership at the final course session. Of 45 such
Table 2 Self-reported personal outcome from participating in the Samson Global Leadership Academy

\begin{tabular}{|ll}
\hline $\begin{array}{l}\text { After participating in the Samson Global Leadership } \\
\text { Academy, participants reported becoming better able to: }\end{array}$ & $\begin{array}{l}\text { Agree and } \\
\text { strongly agree } \\
(\%) \text { N=45 }\end{array}$ \\
\hline Personal competencies & 93 \\
\hline Understand how my emotions affect my behaviour* & 96 \\
\hline Manage my emotional reactions appropriately & 89 \\
\hline Develop strategic organisational plans & 89 \\
\hline Implement strategic plans successfully & \\
\hline Social competencies & 64 \\
\hline Develop positive relationships with patients & 84 \\
\hline Develop positive relationships with clients & 96 \\
\hline Nurture good relationships with peers & 96 \\
\hline Nurture good relationships with subordinates & 93 \\
\hline Nurture good relationships with superiors & 93 \\
\hline Cultivate collaborative teams within my organisation & 93 \\
\hline Develop the abilities of others & 91 \\
\hline Manage interpersonal conflicts in the workplace & 80 \\
\hline Improve patient care & 96 \\
\hline Lead or contribute to organisational change & \\
\hline
\end{tabular}

business plans assessed as of $2007,61 \%$ were deemed impactful, either by being implemented or by 'killing a bad idea fast'. Both outcomes are deemed beneficial. ${ }^{21}$

As a second measure of organisational impact of LHC, to assess the leadership trajectories of course participants, Nowacki et al. $^{23}$ assessed the history of leadership promotion among 272 participants in the first 3 cohorts of LHC. Over the decade following course completion, $43 \%$ of course attendees were promoted to a leadership position within the Cleveland Clinic (eg, department chair, medical executive committee membership and so on) and $18 \%$ were promoted to two or more leadership positions since completing the course. Such promotions can be considered a Kirkpatrick level 3B impact and, to the extent that effective leaders likely effect organisational change, likely predict a 4B level impact. Furthermore, analysis of attendees' baseline Emotional Competency Inventory results showed that three emotional intelligence competencies at baseline were significantly associated $(\mathrm{p}<0.05)$ with leadership promotion: self-confidence, achievement orientation and change catalyst.

Attention has also been given to the impact of long-standing programmes directed to Chief Residents (Chief Residents Leadership Workshop) and to visiting emerging leader healthcare leaders (in the Samson Global Leadership Academy (SGLA)). The Chief Residents Leadership Workshop is a 2-day course offered annually in August (since 2008) to all Chief Residents at Cleveland Clinic and to selected Chief Residents from other training programmes throughout Northeast Ohio and from Cleveland Clinic Florida. Farver $e a^{22}$ assessed the self-reported knowledge impact of participating among 105 attendees of the first 5 offerings of the Chief Residents Leadership Workshop. Preworkshop familiarity with leadership concepts was generally low, with awareness of teambuilding and cultural competence reported to be the best developed (rated 3.0 and 3.18, respectively on a 1-4 Likert scale, where 4 equals very familiar). Similarly, preworkshop comfort levels with personal leadership skills were low, with mentoring (3.35) and conflict skills (3.04) rated higher than the other competencies. Self-reported postworkshop comfort with leadership skills were markedly enhanced, as were participants' impressions about the effectiveness of the 
Table 3 Personal and organisational outcomes from open-ended responses to a survey of Samson Global Leadership Academy alumni

\begin{tabular}{|c|c|c|}
\hline Types of programme outcomes & $\begin{array}{l}\text { Number of participants } \\
(\%), \mathrm{n}=45\end{array}$ & Examples of quotes from participants' open-ended responses \\
\hline \multicolumn{3}{|l|}{ Personal competencies } \\
\hline $\begin{array}{l}\text { Personal competencies } \\
\text { Self-awareness and management }\end{array}$ & $18(40 \%)$ & 'I have better understanding on how my emotions affect my behaviour.' \\
\hline $\begin{array}{l}\text { Social competencies } \\
\text { Communication, relationship Building, talent } \\
\text { development, leadership, collaboration and } \\
\text { teamwork }\end{array}$ & $30(67 \%)$ & $\begin{array}{l}\text { 'Improved performance evaluation and development of teams and action on } \\
\text { underperformers.' }\end{array}$ \\
\hline \multicolumn{3}{|l|}{ Organisational outcomes } \\
\hline $\begin{array}{l}\text { Process improvement } \\
\text { Creation and redesign }\end{array}$ & $23(51 \%)$ & $\begin{array}{l}\text { 'Reorganised to create office of patient experience and office of quality safety and risk } \\
\text { management with physician administrator dyads.' }\end{array}$ \\
\hline $\begin{array}{l}\text { Organisational change } \\
\text { Growth, improvement and change }\end{array}$ & $17(38 \%)$ & $\begin{array}{l}\text { 'Able to influence on the organisational change toward a new model of caring.' } \\
\text { 'Improved and continued organisational growth in both facilities and doctors.' }\end{array}$ \\
\hline $\begin{array}{l}\text { Patient care } \\
\text { Patient experience, safety and quality }\end{array}$ & $10(22 \%)$ & $\begin{array}{l}\text { 'Reducing patient discharge time significantly. We worked on this project and it was a } \\
\text { success story as it dropped from } 120+\text { minutes to } 45 \text { min or less.' }\end{array}$ \\
\hline $\begin{array}{l}\text { Strategic planning } \\
\text { Development and implementation }\end{array}$ & $3(7 \%)$ & $\begin{array}{l}\text { 'Strategic action planning around team engagement activities that resulted in healthy team } \\
\text { engagement results.' }\end{array}$ \\
\hline
\end{tabular}

course. Though the outcomes of this study were self-reported, the study extends available experience with leader development programmes by examining a sparsely studied population-chief residents.

Finally, the Cleveland Clinic has offered the SGLA as an executive education offering to visiting healthcare professionals since 2011. In all, 157 physicians, nurses and administrators from 26 different countries have attended this immersive leader course to date. The SGLA organises its pedagogy around development of self (ie, personal leadership competencies like emotional intelligence and so on) and awareness of systems.

In a survey of 45 SGLA alumni about the impact of the course on their personal leadership behaviour (Kirkpatrick levels 2 and 3 ) and on their organisation (Kirkpatrick level 4), as shown in tables 2 and 3, the large majority of respondents reported gaining personal and social competencies (eg, participating in the course contributed to my being better at managing my emotions, developing the abilities of others and so on). Similarly, most (93\%-96\% of participants) reported that developing a 3 -year leadership plan in the course was personally impactful. In the context that the interval between participation in the course and survey completion was variable and, in some instances, rather short, some reported the view that SGLA participation translated into clear benefits at their organisation (eg, earlier patient discharge, enhanced team engagement and so on).

\section{CONCLUSION}

Overall, in the context that leader development has been the signature feature of leading companies and appears to be a burgeoning interest in healthcare organisations, it is important to assess the impact of such programmes, especially as resources are expended towards them in an era of constrained resources in healthcare. The impact and value of programmes must be addressed individually, and each activity must be contextualised for the culture and priorities of the institution. While some available studies demonstrate value and high organisational impact for such programmes, it appears that rigorous studies are relatively few and that most available studies document self-reported, that is, Kirkpatrick 'A' (vs externally or objectively assessed, level 'B') outcomes. This gap invites further inquiry to assess the impact of such programmes, especially regarding level 4B Kirkpatrick criteria. Also in need of attention is the sustainability of any such impact.
Assessments of the various Cleveland Clinic programmes represent our attempt to assess the impact of physician leader programmes on organisational performance. Future goals for this research are to further examine both the learning, behavioural, and organisational impact of alumni of leader development programmes and to consider their cost-effectiveness (eg, by comparing the programme costs with the financial impact of initiatives led by programme alumni).

Funding The authors have not declared a specific grant for this research from any funding agency in the public, commercial or not-for-profit sectors.

Competing interests None declared.

Patient consent for publication Not required.

Provenance and peer review Not commissioned; externally peer reviewed.

\section{REFERENCES}

1. Stoller JK. Developing physician-leaders: Needneed and rationale. J Health Adm Educ 2009:25:307-28

2. Stoller JK. Help wanted: developing clinician leaders. Perspect Med Educ 2014;3:233-7

3. Lee TH. Turning doctors into leaders. Harv Bus Rev 2010;88:50-8.

4. Stoller JK. Can physicians collaborate? A review of organizational development in healthcare. OD Practitioner 2004;36:19-24.

5. Institute for healthcare improvement, 1991. Available: www.ihi.org/engage/initiatives/ tripleaim/pages/default.aspx [Accessed 3 May 2017].

6. Goodall AH. Physician-leaders and hospital performance: is there an association? Soc Sci Med 2011;73:535-9.

7. Stoller JK GA, Baker A, 2016. Why the best hospitals are managed by doctors. Available: https://hbr.org/2016/12/why-the-best-hospitals-are-managed-by-doctors

8. Tasi MC, Keswani A, Bozic KJ. Does physician leadership affect hospital quality, operational efficiency, and financial performance? Health Care Manage Rev 2017:1.

9. Davidson PL AR, Morrison J, Rocha J. Identifying and developing leadership competencies in health reearch organizations: a pilot study. J Health Adm Ed 2012;29:135-54

10. Lucas R, Goldman EF, Scott AR, et al. Leadership development programs at academic health centers: results of a national survey. Acad Med 2018;93:229-36.

11. Frich JC, Brewster AL, Cherlin EJ, et al. Leadership development programs for physicians: a systematic review. J Gen Intern Med 2015;30:656-74.

12. Kirkpatrick DKJ. Evaluating training programs. 3rd edn. San Francisco: Barrett Koehler Publishers, 2006.

13. Straus SE, Soobiah C, Levinson W. The impact of leadership training programs on physicians in academic medical centers: a systematic review. Acad Med 2013;88:710-23.

14 Day CS, Tabrizi S, Kramer J, et al. Effectiveness of the AAOS leadership fellows program for orthopaedic surgeons. J Bone Joint Surg Am 2010;92:2700-8.

15. West MAK, Lowenthal L, Eckert R, 2015. Leadership and leadership development in health care: the evidence base. Available: https://www.kingsfund.org.uk/sites/default/ 
files/field/field_publication_summary/leadership-in-health-care-apr15.pdf [Accessed 13 Aug 2018].

16. Boyle DK, Kochinda C. Enhancing collaborative communication of nurse and physician leadership in two intensive care units. J Nurs Adm 2004;34:60-70.

17. Dannels SA, Yamagata H, McDade SA, et al. Evaluating a leadership program: a comparative, longitudinal study to assess the impact of the executive leadership in academic medicine (ELAM) program for women. Acad Med 2008;83:488-95.

18. Green PL, Plsek PE. Coaching and leadership for the diffusion of innovation in health care: a different type of multi-organization improvement collaborative. Jt Comm J Qual Improv 2002;28:55-71.

19. Korschun HW, Redding D, Teal GL, et al. Realizing the vision of leadership development in an academic health center: the Woodruff leadership Academy. Acad Med 2007:82:264-71.
20. Richman RC, Morahan PS, Cohen DW, et al. Advancing women and closing the leadership gap: the executive leadership in academic medicine (ELAM) program experience. J Womens Health Gend Based Med 2001;10:271-7.

21. Stoller JK, Berkowitz E, Bailin PL. Physician management and leadership education at the Cleveland Clinic Foundation: program impact and experience over 14 years. J Med Pract Manage 2007;22:237-42.

22. Farver CF, Smalling S, Stoller JK. Developing leadership competencies among medical trainees: five-year experience at the Cleveland Clinic with a chief residents' training course. Australasian Psychiatry 2016;24:499-505.

23. Nowacki ABC, Christensen T, Spencer S, et al. Emotionalintelligence and physician leadership potential: a longitudinalstudy supporting a link. J Health Adm Ed 2016:33:23-41. 